\title{
Acute neonatal citrullinemia type I
}

INSERM

\section{Source}

INSERM. (1999). Orphanet: an online rare disease and orphan drug data base. Acute neonatal citrullinemia type I. ORPHA:247546

Acute neonatal citrullinemia type I is a severe form of citrullinemia type 1 (see this term) characterized biologically by hyperammonemia and clinically by progressive lethargy, poor feeding and vomiting, seizures and possible loss of consciousness, within one to a few days of birth, with variable signs of increased intracranial pressure. The condition can lead to significant neurologic deficits. 